\title{
Molecular changes induced by the curcumin analogue D6 in human melanoma cells
}

\author{
Carla Rozzo ${ }^{1 *}$, Manuela Fanciulli2 ${ }^{2 \dagger}$, Cristina Fraumene ${ }^{2 \dagger}$, Antonio Corrias' ${ }^{1}$, Tiziana Cubeddu ${ }^{2}$, llaria Sassu ${ }^{1}$, \\ Sara Cossu', Valentina Nieddu', Grazia Galleri ${ }^{2}$, Emanuela Azara ${ }^{1}$, Maria Antonietta Dettori ${ }^{1}$, Davide Fabbri ${ }^{1}$, \\ Giuseppe Palmieri ${ }^{1}$ and Marina Pisano ${ }^{1}$
}

\begin{abstract}
Background: In a previous report, we described the in vitro and in vivo antiproliferative and proapoptotic activity of a hydroxylated biphenyl (D6), a structural analogue of curcumin, on malignant melanoma and neuroblastoma tumours. In this paper, we investigated the molecular changes induced by such a compound, underlying cell growth arrest and apoptosis in melanoma cells.

Results: To shed light on the mechanisms of action of D6, we firstly demonstrated its quick cellular uptake and subsequent block of cell cycle in G2/M phase transition. A gene expression profile analysis of D6-treated melanoma cells and fibroblasts was then carried out on high density microarrays, to assess gene expression changes induced by this compound. The expression profile study evidenced both an induction of stress response pathways and a modulation of cell growth regulation mechanisms. In particular, our data suggest that the antiproliferative and proapoptotic activities of D6 in melanoma could be partially driven by up-regulation of the p53 signalling pathways as well as by down-regulation of the PI3K/Akt and NF-kB pathways. Modulation of gene expression due to D6 treatment was verified by western blot analysis for single proteins of interest, confirming the results from the gene expression profile analysis.

Conclusions: Our findings contribute to the understanding of the mechanisms of action of D6, through a comprehensive description of the molecular changes induced by this compound at the gene expression level, in agreement with the previously reported anti-tumour effects on melanoma cells.
\end{abstract}

\section{Background}

Melanoma is the most aggressive form of skin cancer. Its incidence and mortality have risen dramatically in all developed countries during the last half century [1]. Although most cases of melanoma are diagnosed early and surgically resected, later stages of this tumour have very poor survival rates because of the lack of available effective therapies [1-3]. Recently, promising therapeutic approaches for melanoma management have been introduced into the clinical practice, based mostly on the use of small-molecule inhibitors directed against oncogenic molecular targets as well as on immunotherapy [4-7]. However, a high molecular heterogeneity of melanoma tumours and a complex network

\footnotetext{
* Correspondence: carla.rozzo@icb.cnr.it

${ }^{\dagger}$ Equal contributors

${ }^{1}$ Biomolecular Chemistry Institute, National Research Council of Italy. Traversa La Crucca, 3. 07100, Sassari, ITALY

Full list of author information is available at the end of the article
}

of proliferation and survival pathways involved in its pathogenesis have been reported [8,9]. For this reason, there is a growing interest in seeking pharmacological agents that could target multiple gene products in order to interfere, at different levels, with pathogenetic pathways in melanoma. During the last decades, several dietary agents have been reported to exert anticancer activity. They commonly show multifaceted effects on cancer cells by inducing molecular changes related to different mechanisms of carcinogenesis: proliferation, apoptosis, invasion, and metastasis [10]. An innovative therapeutic approach to manage melanoma may be represented by the introduction into clinical trials of naturally occurring compounds (such as eugenol, resveratrol, green tea, curcumin and other), whose antiproliferative and/or proapoptotic activity against malignant melanoma - in both in vitro and in vivo models - has been already demonstrated [11]. Among them, curcumin, a polyphenol extracted from the rhizome

\section{Biomed Central}


of the plant Curcuma longa, has been frequently reported to exert promising anticancer activity on several tumours [12]. This molecule is highly pleiotropic, is able to enter cells [13], and interacts with numerous targets [14]. Strong evidence demonstrated that curcumin inhibits proliferation, invasion, angiogenesis, and metastasis in several types of cancer through interaction with multiple cell signalling proteins (reviewed in $[15,16]$ ). Recently, curcumin has been shown to exert a good antiproliferative activity by inducing apoptosis in malignant melanoma [17]. One of the most important pathway involved in the curcumin antitumour activity is the nuclear factor-kB (NF-kB) pathway [18], particularly in melanoma cells. Indeed, curcumin is able to suppress the activation and phosphorylation of the inhibitor of NF-kB alpha ( $\mathrm{IkBa}$ ) by inhibiting the IkB kinase (IKK) and NF-kB activity in human melanoma cell lines [19,20]. Moreover, curcumin induces cell apoptosis and cell cycle arrest in G2/M phase in melanoma, through up-regulation of p53, p21, p27 and checkpoint kinase 2 [19].

Recently, our group has synthesized a new curcuminrelated biphenyl structure (an $\alpha \beta$ unsaturated ketone called D6) whose antiproliferative and proapoptotic activities on melanoma cell lines were more effective, rapid and selective than those induced by curcumin. The D6 compound was proved to promote apoptosis in melanoma cells through the mitochondrial intrinsic pathway [21]. In vivo assays on mouse models confirmed the potential of D6 against melanoma, showing a significant reduction of the tumour mass growth as compared to untreated control [21].

To investigate the mechanisms of action of the D6curcumin analogue against melanoma at the molecular level, we here studied its cellular uptake and its influence on cell cycle progression. Finally, a gene expression profile analysis of D6-treated melanoma cell lines was carried out on high density microarrays, in order to explore the molecular pathways activated after D6 enters cells. This genomic technology is useful to dissect the molecular changes occurring inside cancer cells, and it is well documented for malignant melanoma [22,23]. In our study, the LB24Dagi (LB24) primary melanoma cell line was selected for all the analyses, because it had been previously demonstrated to be the most sensitive line to D6 treatment among tested ones [21]. Several molecular changes that can justify the antiproliferative and proapoptotic properties of D6 on melanoma cells and likely contribute to its anti-tumour effect have been here presented and discussed.

\section{Results}

\section{D6 enters melanoma cells}

To verify the ability of D6 (Figure 1A) to enter melanoma cells, as demonstrated for curcumin in different cancer cells [13], we performed cellular uptake studies. After a 24 hours time course treatment, D6 cellular uptake was estimated by LC-MS on methanol cell lysates, as described in Methods. Comparison of D6 peak area for each sample to a calibration curve allowed us to calculate intracellular D6 concentration at different times. Data reported in Figure 1B show that the highest cellular D6 concentration (about $270 \mathrm{nM}$, corresponding to approximately 600 pmoles $/ 10^{6}$ cells) was reached two hours after treatment. These results indicated that D6 presents the same time of uptake of curcumin in other cancer cells and is able to enter melanoma cells about 15 folds more efficiently than curcumin itself (34-44 pmoles/10 ${ }^{6}$ cells [13]).

\section{D6 blocks cell cycle at G2/M transition}

To evaluate the effect of D6 treatment on melanoma cell cycle progression, we performed flow cytofluorimetric analysis on LB24 cells treated with either 5 or $10 \mu \mathrm{M}$ D6 for 24 hours and stained with propidium iodide, as described in Methods. Results obtained are summarized in Figure 2. A significant enrichment in $\mathrm{G} 2 / \mathrm{M}$ cell populations was observed at both $5 \mu \mathrm{M}(21.65 \%)$ and $10 \mu \mathrm{M}$ (26.13\%) concentrations of D6 treatment, as compared to untreated cells $(11.0 \%)$ ( $\mathrm{P}<0.05$ and $<0.001$ respectively) (Figure $2 \mathrm{~A}$ ). As a consequence, a significant reduction of G0/G1 phase cell population confirms the cell cycle arrest in G2 as an effect of melanoma cells exposure to D6. Figure 2B shows representative cell cycle histograms with a consistent increase in $S$ phase cell number, indicating an accumulation of cells that do not trespass the G2/M checkpoint. Altogether, such findings strongly suggest that block of cell cycle progression may represent one of the mechanisms by which D6 inhibits melanoma cells growth (as previously observed by our group [21]).

\section{D6 treatment induces transcriptional changes in melanoma cells and normal fibroblasts}

To analyze gene expression modifications induced by D6 treatment on melanoma cells, we carried out gene expression profile analyses on LB24 primary melanoma cell line, either treated or not (negative control) with $10 \mu \mathrm{M}$ D6, using high density microarrays (see Methods). Same analysis was performed on human fibroblasts cells (BJ cell line) as normal control, which have been previously demonstrated to be insensitive to D6 [21].

Gene expression results were firstly filtered, in order to avoid analysis of background detection values (see Methods). Overall, 18,798 probes, representing the effective gene expression profiles of cell populations examined, were selected to perform the statistical analysis. This allowed the identification of gene transcripts whose expression was modulated by D6 treatment in each of the two cell types. Gene expression values obtained from D6 treated cells were compared with those obtained from untreated cells and fold change values (FC) were determined. For each cell population, 


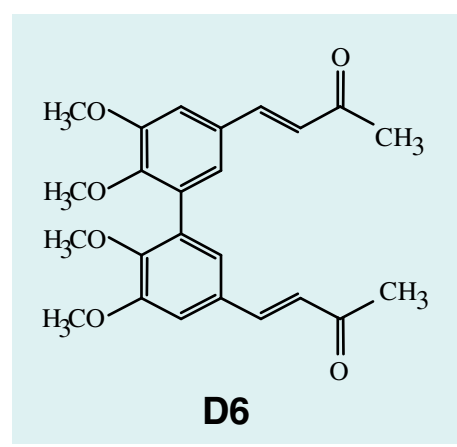

A

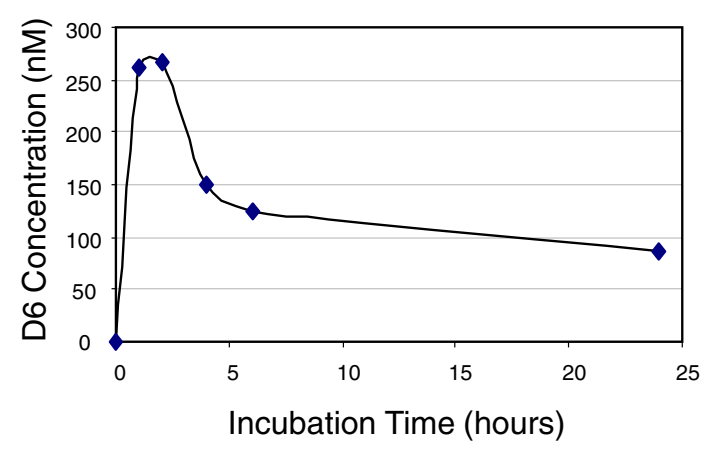

B

Figure 1 D6 cellular uptake. A: molecular structure of the curcumin-related biphenyl compound, the aß-unsaturated ketone D6 ( $\left.3 E, 3^{\prime} E\right)-4$, 4'-(5,5',6,6'-tetramethoxy-[1,1'-biphenyl]-3,3'-diyl)bis(but-3-en-2-one); B: intracellular D6 mean concentrations following incubation of LB24 cells with $10 \mu \mathrm{M}$ D6 for the indicated times. Mean values were calculated by the LC/MS method.

probes showing $\mathrm{FC}$ values above 2 (double intensity or more, over-expression) or under 0.5 (half intensity or less, under-expression) (0.5 > FC > 2) among treated and untreated samples were selected. Such comparison resulted in two lists of genes differentially expressed in either LB24 melanoma cells [1,173 probes (719 genes, excluding redundancies); $6.2 \%$ of the 18,798 analysed ones] (Additional file 1 -A) and in BJ fibroblast $[1,883$ probes (1,177 genes, excluding redundancies); $10 \%$ ] (Additional file 2-A). In particular, $3.6 \%$ and $2.6 \%$ analysed transcripts were over- and under-expressed in melanoma cells, respectively. In fibroblasts, the trend of percentages was instead opposite $(5.2 \%$ under- and $4.8 \%$ over-expressed transcripts) (Table 1).

The two lists of selected probes were analysed by the Ingenuity Pathway Analysis (IPA) software. Results obtained on melanoma cells are reported in Additional file 1-B and 1-C. IPA results obtained for BJ fibroblasts are reported in Additional file 2-B and 2-C.

\section{D6 treatment affects cell death and proliferation bio- functions}

The top bio-functional categories identified by IPA among the genes modulated in treated melanoma cells are listed in Table 2, where the p-values range and number of molecules involved are reported for each category (see the complete list in Additional file 1-B).

The lowest $p$-values were found for the Cell Death category with 194 molecules involved (Table 2, n. 1). Cell death is indeed the primary effect detected on melanoma cells after D6 treatment [21]. Moreover, a variable number

\begin{tabular}{clllllll}
\hline & \multicolumn{1}{c}{ A } & \multicolumn{2}{c}{ G6 conc. 1} & \multicolumn{2}{c}{ S-phase } & \multicolumn{2}{c}{ G2/M } \\
\hline \hline 0 $\mu \mathrm{M}$ & 56.94 & 6.3 & 31.36 & 9.8 & 11.00 & 4.1 \\
$5 \mu \mathrm{M}$ & 37.02 & $12.2^{* *}$ & 41.32 & 20.2 & 21.65 & $8.4^{*}$ \\
$10 \mu \mathrm{M}$ & 40.37 & $2.1^{* *}$ & 33.49 & 2.3 & 26.13 & $1.4^{* *}$ \\
\hline \hline
\end{tabular}

B
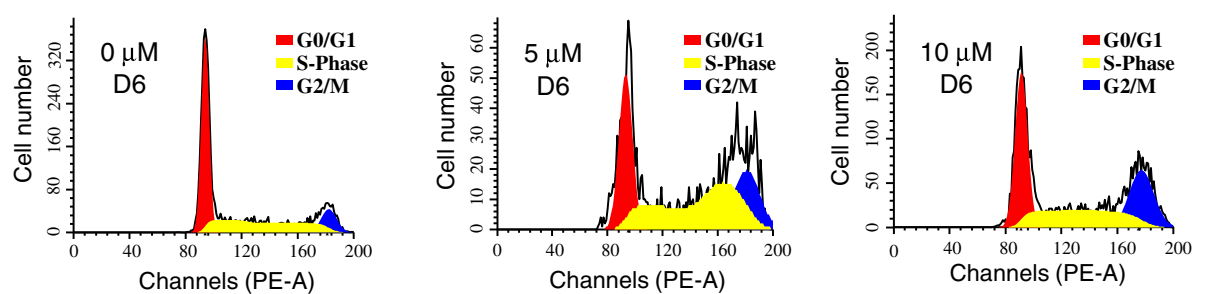

Figure 2 Cell cycle progression analysis. Cytofluorimetric analysis results from LB24 cells, untreated or treated with D6 for 24 hours. A: the table summarizes the percentage mean values \pm SD of each cell cycle phase cell populations, obtained in three independent experiments. T-test was performed independently for each phase considering untreated $(0 \mu \mathrm{M})$ versus treated ( 5 and $10 \mu \mathrm{M}$ D6 respectively) cells. ${ }^{*} P<0.05,{ }^{* *} P<0.001$; B: DNA content frequency histograms representing cells from untreated $(0 \mu \mathrm{M})$ or 5 and $10 \mu \mathrm{M}$ D6 treated LB24 cells. The histograms are referred to one, representative of three independent experiments. 
Table 1 Transcriptional changes induced by D6 treatment in melanoma cells and normal fibroblasts

\begin{tabular}{|c|c|c|c|}
\hline Cell type & $\begin{array}{c}\text { Differentially } \\
\text { expressed transcripts }\end{array}$ & $\begin{array}{c}\text { Over- } \\
\text { expressed }\end{array}$ & $\begin{array}{c}\text { Under- } \\
\text { expressed }\end{array}$ \\
\hline & $(0.5>$ FC $>2)$ & $(F C>2)$ & $(\mathrm{FC}<0.5)$ \\
\hline $\begin{array}{l}\text { LB } 24 \text { DAGI } \\
\text { Melanoma cells }\end{array}$ & $1173(6.2 \%)$ & $681(3.6 \%)$ & $492(2.6 \%)$ \\
\hline BJ Fibroblasts & $1883(10 \%)$ & $910(4.8 \%)$ & $973(5.2 \%)$ \\
\hline
\end{tabular}

Results from the statistical analysis conducted on microarrays gene expression data from LB24 melanoma cells and BJ fibroblasts, treated or not with $10 \mu \mathrm{M}$ D6, are reported. Data shown represent the number / (percentages) of human transcripts that resulted differentially expressed $(0.5>\mathrm{FC}>2)$ by comparing treated and not treated samples. Detailed gene expression profile and statistical analysis procedures are described in the Methods section.

of molecules differentially modulated by D6 involved functional categories strictly correlated with cell proliferation processes such as cellular function and maintenance, cell cycle and cell growth and proliferation (Table 2, n. 2-5).

D6 induces stress response pathways and down-regulates cell proliferation pathways

Table 3 lists the most significant pathways $(p<0.05)$ that IPA found to be enriched with the input genes in melanoma cells (a complete list is reported in Additional file 1C). For each pathway, the respective nominal $p$-value, along with all the input molecules are reported (Table 3 ).

A general trend of up-regulation for pathways involving cell stress response was evident (Figure 3, red bars); conversely, pathways that control cell proliferation appeared down-regulated (Figure 3, green bars).

The first three most significant pathways, 1-Aldosterone signalling, 2-Protein ubiquitination, and 3-NRF2 mediated oxidative stress response as well as the 21-Endoplasmic reticulum stress pathway appear to be up-regulated (Table 3; Figure 3), depicting a strong activation of stress induced molecular responses that involves over-expression of heat shock proteins (HSPs) and activation of protein degradation processes. Among up-regulated HSPs, HSPA6 is the most over-expressed transcript in melanoma treated cells with a

Table 2 Melanoma top bio functions

\begin{tabular}{llcc}
\hline Bio-Function & \multicolumn{1}{c}{$\boldsymbol{p}$-value } & N. of molecules \\
\hline $\mathbf{1}$ & Cell death & $3.34 \mathrm{E}-15-3.24 \mathrm{E}-02$ & 194 \\
\hline $\mathbf{2}$ & $\begin{array}{l}\text { Cellular function } \\
\text { and maintenance }\end{array}$ & $6.17 \mathrm{E}-14-3.24 \mathrm{E}-02$ & 64 \\
\hline $\mathbf{3}$ & Cancer & $1.22 \mathrm{E}-13-3.24 \mathrm{E}-02$ & 306 \\
\hline $\mathbf{4}$ & Cell cycle & $9.64 \mathrm{E}-12-3.15 \mathrm{E}-02$ & 113 \\
\hline $\mathbf{5}$ & $\begin{array}{l}\text { Cellular growth and } \\
\text { proliferation }\end{array}$ & $1.16 \mathrm{E}-11-3.15 \mathrm{E}-02$ & 204 \\
\hline
\end{tabular}

Top five bio-functional categories identified by IPA software by analysing the 1,173 transcripts modulated in $10 \mu \mathrm{M}$ D6 treated LB24 melanoma cells are reported. The $p$-value reflects the significance of the enrichment of input genes in each functional category. The complete list is reported in Additional File 1-B.
FC value of 368.61 (Table 4). HSPA6 codifies for the Hsp70B', a highly stress inducible protein.

Additional pathways such as 4 -Cell cycle: G2/M DNA damage checkpoint regulation, 5 -p53 signalling, 10 -Hereditary breast cancer signalling, 11 -ATM signalling, 26 Role of BRCA1 in DNA damage response, and 27 -Role of CHK proteins in cell cycle checkpoint control are all related to DNA repair mechanisms and cell death triggering (Table 3 and Additional files 3, 4, 5, 6, 7, 8), evidencing a DNA damage as cell response to D6 treatment.

The up-regulation of pathway 5- p53 signalling (Figure 3, Additional file 4), which acts in response to cell injury or DNA damage by controlling cell proliferation and driving cells to apoptosis, is noteworthy and points out a central role of this regulatory protein in the D6 anticancer effect on melanoma cells. Indeed, induction of p53 activity was evidenced by up-regulation of some p53 target genes: $C D K N 1 A(\mathrm{FC}=19.35), G A D D 45 A$ and $B(\mathrm{FC}=7.78$ and $\mathrm{FC}=7.47$, respectively), all codifying for inhibitors of the cell cycle, and PMAIP1 $(\mathrm{FC}=6.08)$ codifying for Noxa, a pro-apoptotic $\mathrm{BH} 3$ only protein of the $\mathrm{Bcl} 2$ family (Table 4 ). A slight up-regulation of TP53BP2 gene $(\mathrm{FC}=2.36)$, codifying for ASSP2 - a member of the ASPP (apoptosis-stimulating protein of p53) family of p53 interacting proteins, confirms the role of p53 as an apoptosis activator in our system.

Down-regulation of pathways controlling cell proliferation such as pathways 4-Cell cycle:G2/M DNA damage checkpoint regulation, 8 -Mitotic roles of PLK, 13 -Cyclins and cell cycle regulation, 23 -Molecular mechanisms of cancer and 25 -Cell cycle: G1/S checkpoint regulation was also observed (Figure 3, green bars). These alterations seem to be related to the down-regulation of important cell-cycle "motors" like CCNB1/2 (cyclin B1 and 2), CDC25, and CDK4 (Tables 3 and 4, Additional files 3, 9, 10, 11, 12).

Other interesting features highlighted by the pathway analysis are the partial down regulation of phosphatidylinositol 3 kinase - regulatory subunit 2 (PIK3R2, FC = $0.48)$ and nuclear factor-kB1 $(N F K B 1, \mathrm{FC}=0.47)$ genes (Table 4). On this regard, both PIK3R2 and NFKB1 are greatly represented in the melanoma most significant pathways listed in Table 3 (19 and 13 out of 42 pathways, respectively).

\section{D6 modulates the expression of several life and death regulator genes}

Beside the modulated genes highlighted by the pathway analysis, FC analysis evidenced some other genes whose modulation might have a role in the observed antiproliferative and pro-apoptotic activities of D6 on melanoma cells (Additional file 1-A) [21]. Among them, the CCNF gene that codifies for the G2/mitotic-specific cyclin-F was highly down-modulated $(\mathrm{FC}=0.24$, Table 4$)$. Cyclin F is produced in the G2 cell cycle phase and is 
Table 3 Melanoma top canonical pathways

\begin{tabular}{ll}
\hline Ingenuity canonical pathways & Nominal $\boldsymbol{p}$-value \\
\hline $\mathbf{1} \begin{array}{l}\text { Aldosterone Signaling in } \\
\text { Epithelial Cells }\end{array}$ & $2.81838 \mathrm{E}-06$
\end{tabular}

2 Protein Ubiquitination Pathway 3.98107E-06

\begin{tabular}{llc}
\hline $\mathbf{3}$ & $\begin{array}{l}\text { NRF2-mediated Oxidative } \\
\text { Stress Response }\end{array}$ & 7.58578E-05 \\
\hline $\mathbf{4}$ & $\begin{array}{l}\text { Cell Cycle: G2/M DNA Damage } \\
\text { Checkpoint Regulation }\end{array}$ & 0.000177828 \\
\hline $\mathbf{5}$ & p53 Signaling & 0.000194984 \\
\hline $\mathbf{6}$ & VDR/RXR Activation & 0.000446684 \\
$\mathbf{7}$ & Pyrimidine Metabolism & 0.001
\end{tabular}

\begin{tabular}{lll}
\hline $\mathbf{8}$ & $\begin{array}{l}\text { Mitotic Roles of Polo-Like } \\
\text { Kinase }\end{array}$ & 0.002089296 \\
\hline $\mathbf{9}$ & IGF-1 Signaling & 0.002818383 \\
\hline $\mathbf{1 0}$ & $\begin{array}{l}\text { Hereditary Breast Cancer } \\
\text { Signaling }\end{array}$ & 0.003467369 \\
\hline $\mathbf{1 1}$ & ATM Signaling & 0.003890451 \\
\hline $\mathbf{1 2}$ & RAR Activation & 0.004265795
\end{tabular}

\begin{tabular}{|c|c|c|c|}
\hline 13 & $\begin{array}{l}\text { Cyclins and Cell Cycle } \\
\text { Regulation }\end{array}$ & 0.004677351 & PPP2CB, E2F6, TFDP1, CDK4, SUV39H1, CDKN1A, E2F5, CCNB2, SKP2 (includes EG:27401), CCNB1 \\
\hline 14 & p38 MAPK Signaling & 0.005495409 & $\begin{array}{l}\text { FADD, DDIT3, DUSP1, DUSP10, MEF2D, H3F3A/H3F3B, ATF4, MAP2K3, MKNK2, EEF2K, } \\
\text { H3F3C, IRAK2 }\end{array}$ \\
\hline 15 & $\begin{array}{l}\text { Pancreatic Adenocarcinoma } \\
\text { Signaling }\end{array}$ & 0.005888437 & VEGFA, HMOX1, E2F6, TFDP1, CDK4, SUV39H1, CDKN1A, E2F5, HBEGF, PIK3R2, ERBB2, NFKB1 \\
\hline 16 & Renal Cell Carcinoma Signaling & 0.00691831 & VEGFA,ETS1,FOS,JUN,NRAS,SLC2A1,CRK,PIK3R2,UBC \\
\hline 17 & $\begin{array}{l}\text { Cell Cycle Regulation by BTG } \\
\text { Family Proteins }\end{array}$ & 0.00691831 & PPP2CB,E2F6,CDK4,E2F5,BTG1,CCRN4L \\
\hline 18 & $\begin{array}{l}\text { Retinoic acid Mediated } \\
\text { Apoptosis Signaling }\end{array}$ & 0.007585776 & FADD,TNKS,CRABP2,TNFRSF10B,TNFRSF10D,RXRA,TIPARP,IRF1 (includes EG:16362) \\
\hline 19 & $\begin{array}{l}\text { Glucocorticoid Receptor } \\
\text { Signaling }\end{array}$ & 0.008912509 & $\begin{array}{l}\text { IL8,NRAS,HSPA7,SGK1,HSPA1A/HSPA1B,HSPA6,NFKB1,HSPA5,TAF13 (includes EG:310784), } \\
\text { FOS,HSPA4,GTF2B,TAF6L,JUN,TAF4 (includes EG:100149942),HSPA1L,DUSP1,CDKN1A,FKBP4, } \\
\text { PRKAG2,PIK3R2,CSF2 }\end{array}$ \\
\hline 20 & Toll-like Receptor Signaling & 0.01023293 & FOS,LY96 (includes EG:17087),JUN,CD14,MAP2K3,NFKB1,IRAK2 \\
\hline 21 & $\begin{array}{l}\text { Endoplasmic Reticulum Stress } \\
\text { Pathway }\end{array}$ & 0.010715193 & DNAJC3,ATF4,HSPA5,EIF2AK3 \\
\hline 22 & Neurotrophin/TRK Signaling & 0.013489629 & FOS,JUN,NRAS,SPRY1,ATF4,MAP2K3,PIK3R2,FRS2 \\
\hline 23 & $\begin{array}{l}\text { Molecular Mechanisms } \\
\text { of Cancer }\end{array}$ & 0.015488166 & $\begin{array}{l}\text { BMP4,SUV39H1,BMP2,CRK,SMAD5,NFKB1,CDC25B,E2F6,JUN,E2F5,PIK3R2,BRCA1,LRP5, } \\
\text { PMAIP1,NRAS,STK36,TFDP1,ADCY3,AURKA,FADD,FOS,RND3,CDK4,CDKN1A,PRKAG2,MAP2K3 }\end{array}$ \\
\hline 24 & $\begin{array}{l}\text { Chronic Myeloid Leukemia } \\
\text { Signaling }\end{array}$ & 0.015848932 & E2F6,NRAS,TFDP1,CDK4,SUV39H1,CDKN1A,E2F5,CRK,PIK3R2,NFKB1 \\
\hline 25 & $\begin{array}{l}\text { Cell Cycle: G1/S Checkpoint } \\
\text { Regulation }\end{array}$ & 0.016982437 & E2F6,TFDP1,CDK4,SUV39H1,CDKN1A,E2F5,SKP2 (includes EG:27401) \\
\hline 26 & $\begin{array}{l}\text { Role of BRCA1 in DNA Damage } \\
\text { Response }\end{array}$ & 0.018620871 & E2F6,GADD45A,FANCG,CDKN1A,E2F5,RFC5,BRCA1 \\
\hline 27 & $\begin{array}{l}\text { Role of CHK Proteins in Cell } \\
\text { Cycle Checkpoint Control }\end{array}$ & 0.022387211 & E2F6,CDKN1A,E2F5,RFC5,BRCA1 \\
\hline 28 & Bladder Cancer Signaling & 0.028840315 & VEGFA,IL8,NRAS,TFDP1,THBS1,CDK4,SUV39H1,CDKN1A,ERBB2 \\
\hline 29 & IL-17A Signaling in Gastric Cells & 0.033113112 & IL8,FOS,JUN,NFKB1 \\
\hline
\end{tabular}

Genes

CRYAB,HSPA7,SGK1,DNAJB4,HSPA1A/HSPA1B,HSPH1,SLC12A2,HSPA6, DNAJC3, HSPD1,DNAJB2,DNAJB9,HSPA5,DNAJA1,DNAJB14,HSPA4,HSPA1L,DUSP1,HSPA13 PIK3R2,DNAJB6,DNAJB1,HSPA4L

CRYAB,UBE2H,HSPA7,DNAJB4,HSPA1A/HSPA1B,HSPA6,DNAJC3,DNAJB2, HSPA5, DNAJA1,HSPA4,HSPA1L,STUB1,HLA-B, DNAJB1, BRCA1, HSPA4L, MED20, HSPH1, PSMC4, USP30, HSPD1, DNAJB9, DNAJB14, SKP2 (includes EG:27401), ANAPC4, PSMD12, HSPA13, DNAJB6, UBC, UBE2D3

NRAS,DNAJB4,HERPUD1,DNAJC3,DNAJB2,DNAJA1,DNAJB9,DNAJB14,MAFF, TXNRD1, FOS, HMOX1, JUN, ATF4, MAP2K3, FOSL1, PIK3R2, SQSTM1, DNAJB6, DNAJB1, GCLM, EIF2AK3 CDC25B, GADD45A, CDKN1A, TOP2A, CCNB2, PKMYT1, BRCA1, SKP2 (includes EG:27401), CCNB1

PMAIP1, GADD45B, THBS1, TNFRSF10B, TP53BP2, SERPINE2, SCO2 (includes EG:606683), JUN, GADD45A, CDK4, ADCK3, CDKN1A, PIK3R2, BRCA1

GTF2B,LRP5, GADD45A, MXD1, HOXA10, CDKN1A, IGFBP3, CD14, CST6 (includes EG:1474), CSF2, RXRA, KLF4

POLE2, DCTPP1, UPP1, POLQ, DKC1, DTYMK, RFC5, POLRMT, PUS1, TXNRD1, POLR1C, POLD3, PNP, POLA2, UNG, ENTPD7

CDC25B, PPP2CB, ANAPC4, PLK2, CDC7 (includes EG:12545), cCNB2, PKMYT1, ANAPC13, CCNB1 SOCS1, CSNK2A2, FOS, JUN, NRAS, CTGF, NOV, IGFBP3, PRKAG2, IRS2, PIK3R2, CYR61 NRAS, GADD45B, FANCG, RFC5, CCNB1, PALB2, GADD45A, CDK4, XPC, CDKN1A, PIK3R2, UBC, BRCA1

JUN, GADD45B, GADD45A, CDKN1A, CCNB2, ATF4, BRCA1, CCNB1

RDH14, BMP2 ,CSK, ADCY3, SMAD5, NFKB1, VEGFA, FOS, CSNK2A2, JUN, TAF4 (includes G:100149942), DUSP1, CRABP2, IGFBP3, PRKAG2, PIK3R2, RXRA (1) 
Table 3 Melanoma top canonical pathways (Continued)

\begin{tabular}{|c|c|c|c|}
\hline 30 & Role of Tissue Factor in Cancer & 0.036307805 & VEGFA,IL8,NRAS,CTGF,ARRB1,PLAUR,HBEGF,PIK3R2,CSF2,CYR61 \\
\hline 31 & HMGB1 Signaling & 0.038904514 & IL8,FOS,JUN,NRAS,RND3,MAP2K3,PIK3R2,NFKB1,KAT2A \\
\hline 32 & ERK/MAPK Signaling & 0.039810717 & $\begin{array}{l}\text { ETS1,NRAS,H3F3A/H3F3B,CRK,MKNK2,PPP1R14B,H3F3C,FOS,PPP2CB,ELF3,DUSP1,PRKAG2,ATF4, } \\
\text { DUSP4,PIK3R2 }\end{array}$ \\
\hline 33 & $\begin{array}{l}\text { Non-Small Cell Lung Cancer } \\
\text { Signaling }\end{array}$ & 0.041686938 & NRAS,TFDP1,CDK4,SUV39H1,PIK3R2,ERBB2,RXRA \\
\hline 34 & Prostate Cancer Signaling & 0.041686938 & NRAS,TFDP1,SUV39H1,CDKN1 A,NKX3-1,ATF4,PIK3R2,NFKB1 \\
\hline 35 & RAN Signaling & 0.042657952 & CSE1L,XPO1,RANBP1 \\
\hline 36 & $\begin{array}{l}\text { Cell Cycle Control of } \\
\text { Chromosomal Replication }\end{array}$ & 0.042657952 & MCM3,CDK4,ORC5 (includes EG:26429),CDC7 (includes EG:12545) \\
\hline 37 & IL-6 Signaling & 0.043651583 & IL8,SOCS1,CSNK2A2,FOS,JUN,NRAS,CD14,MAP2K3,NFKB1 \\
\hline 38 & IL-2 Signaling & 0.046773514 & SOCS1,CSNK2A2,FOS,JUN,NRAS,PIK3R2 \\
\hline 39 & $\begin{array}{l}\text { MIF Regulation of Innate } \\
\text { Immunity }\end{array}$ & 0.046773514 & FOS,LY96 (includes EG:17087),JUN,CD14,NFKB1 \\
\hline 40 & $\begin{array}{l}\text { Role of IL-17F in Allergic } \\
\text { Inflammatory Airway Diseases }\end{array}$ & 0.046773514 & IL8,ATF4,SIK1,CSF2,NFKB1 \\
\hline 41 & Erythropoietin Signaling & 0.047863009 & SOCS1,FOS,PTPN6,JUN,NRAS,PIK3R2,NFKB1 \\
\hline 42 & Estrogen Receptor Signaling & 0.048977882 & $\begin{array}{l}\text { TAF6L,GTF2B,NRAS,TAF4 (includes EG:100149942), MED20, H3F3A/H3F3B, MED16,HNRNPD, } \\
\text { TAF13 (includes EG:310784),MED10,H3F3C }\end{array}$ \\
\hline
\end{tabular}

Most significant pathways (nominal $p$-value $<0.05$ ) identified by IPA software by analysing the 1,173 transcripts modulated in $10 \mu \mathrm{M}$ D6 treated LB24 melanoma cells are reported. The $p$-value reflects the significance of the enrichment of input genes in each pathway. The complete list is reported in Additional File 1-C. Genes discussed in the text and HSPs are evidenced by bold characters.

essential for fidelity of mitosis; therefore, a downmodulation of such protein may interfere with the progression of cell division, which is consistent with the block of cell cycle in G2/M phase observed upon D6 treatment (Figure 2).

Among the down-regulated genes $(\mathrm{FC}<0.5)$, we found an evident under-expression of the $c$-KIT proto-oncogene $(\mathrm{FC}=0.30)$, whose activation is often associated with increased cell proliferation, specifically in melanoma (Table 4) [24]. Down regulation of $c-K I T$ is then likely to be related to D6 anticancer activity on melanoma cells, contributing to inhibit cell-proliferation signals.

We already demonstrated that D6 treatment induces apoptosis in melanoma cells through the mitochondrial intrinsic pathway [21]. Looking at gene expression levels of the apoptosis-related genes, we observed a strong up-

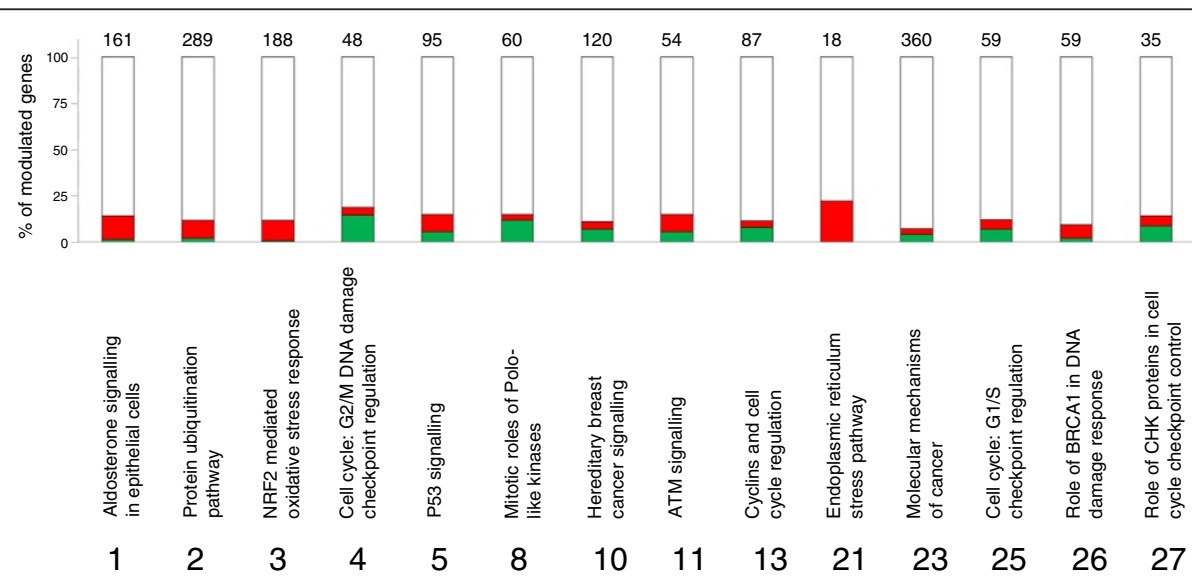

\section{$\square$ Downregulated \\ $\square$ Upregulated \\ No overlap with dataset}

Figure 3 Melanoma significant pathways. Diagram of most representative pathways modulated by D6 treatment in melanoma cells. $\mathrm{X}$ axes: representative molecular pathways. Pathways are numbered according to Table 3; Y axes: percentage of D6 modulated genes for each pathway. Numbers on top of the columns represent the total number of genes involved in each pathway. 
Table 4 Melanoma modulated genes

\begin{tabular}{|c|c|c|}
\hline \multirow[t]{2}{*}{ GENE } & \multicolumn{2}{|c|}{ FC } \\
\hline & LB & BJ \\
\hline HSPA6 & 368.61 & 480.00 \\
\hline HSPA1A & 20.35 & 12.38 \\
\hline CDKN1A & 19.35 & 4.29 \\
\hline DDIT3 & 11.11 & 9.11 \\
\hline GADD45A & 7.78 & 6.00 \\
\hline GADD45B & 7.47 & 14.90 \\
\hline PMAIP1 & 6.08 & 7.72 \\
\hline $\mathrm{BCL} 10$ & 3.93 & 2.02 \\
\hline TP53BP2 & 2.36 & - \\
\hline CCNF & 0.24 & - \\
\hline KIT & 0.30 & - \\
\hline CDK4 & 0.43 & 0.43 \\
\hline CCNB1 & 0.43 & - \\
\hline CDC25B & 0.47 & - \\
\hline NFKB1 & 0.47 & - \\
\hline PIK3R2 & 0.48 & - \\
\hline
\end{tabular}

Genes differentially expressed in LB24 melanoma cells after D6 treatment are reported. The most significant genes possibly related to D6 antiproliferative and pro-apoptotic effects as well as their relative fold change values (FC) in either LB24 melanoma cells or BJ fibroblasts are presented. The complete lists of differentially expressed genes and relative FC for each cell line are reported in the Additional files 1-A and 2-A respectively.

regulation of DDIT3 (DNA-damage-inducible transcript 3 , FC $=11.1$, a transcription factor activated in endoplasmic reticulum stress conditions that promotes apoptosis by induction of caspases [25], as well as a discrete overexpression of the gene $B C L 10$ ( $\mathrm{FC}=3.93)$, encoding for a pro-apoptotic member of the $\mathrm{Bcl} 2$ family proteins [26], in addition to the over-expression of the protein Noxa codified by PMAIP1 mentioned above $(\mathrm{FC}=6.08$ ) (Table 4 ). These are further evidences about the involvement of proapoptotic signals in D6 treated cells.

\section{Expression profile changes in D6 treated fibroblasts}

The IPA-based analysis of the 1,883 transcripts modulated by D6 in fibroblasts (listed in Additional file 2-A) was useful to compare results with those obtained in melanoma cells. Biological function categories found to be significant in fibroblasts were similar to those selected for melanoma cells (Additional file 2-B), suggesting that D6 treatments involve life and death controlling mechanisms also in normal cells. However, D6 treated fibroblasts did not show significant effects in terms of block of proliferation or induction of apoptosis, as we previously described [21]. The analysis of D6 treated fibroblasts evidenced the involvement of the pathways underlying general cell stress responses (Additional file 2-C). However, processes including chaperones activation and protein degradation were less significant in fibroblasts than in melanoma cells (Additional file 2-C, pathways 10, 16, 21), with some HSPs being down-modulated. Conversely, DNA damage induced cell response pathways were highly significant in fibroblasts also (see Additional file 2-C, pathways 2, 3, 4, 5, 9, 18), indicating that D6 even triggers an anti-mitotic reaction in normal cells (though not confirmed in the biological assays [21]). Such a response was anyway weaker in these latter cells and pathway trends markedly differed between melanoma and fibroblasts (i.e., p21/CDKN1A, FC = 19.35 in melanoma cells versus $\mathrm{FC}=4.29$ in fibroblasts, or CCNB1, $\mathrm{FC}=0.43$ and $C D C 25 B, \mathrm{FC}=0.47$ in melanoma cells with no modulation in fibroblasts; Table 4). Furthermore, neither PIK3R2 nor NFKB1 gene expressions were altered in fibroblasts, suggesting that the relative pathways are not hindered by D6 in these normal cells. These data suggest that D6 interaction with both PI3K/Akt and NF-kB signal transduction cascades may be peculiar of its activity on cancer cells.

\section{Protein levels reflect gene expression changes in D6 treated melanoma cells}

Protein levels for most of the differentially expressed genes above mentioned were verified by western blot on LB24 cells (Figure 4), in order to confirm that D6-induced modulation of expression at mRNA levels was indeed maintained at protein levels.

Figure 4A shows the increased protein levels detected by western blot for the three major p53 targets modulated by D6: p21, GADD45A, and Noxa. The p21 protein was about 2.5 fold more expressed in treated cells compared to the untreated ones, confirming the increase of CDKN1A gene expression. Same increased levels were observed for the GADD45-A protein, while Noxa protein levels were about 70\% higher as compared to those of control cells.

Among the proteins involved in regulation of cell cycle G2/M phase transition, we performed immunoblot assays for cyclin B, cdc25, and cyclin F. Protein levels detected in D6 treated cells were much lower than those of untreated ones, thus confirming the decrease of expression observed in microarrays analysis (Figure 4B).

An almost complete depletion of the PI3K protein in treated cells compared to untreated ones is shown in Figure $4 \mathrm{C}$, reflecting the under-expression of the PIK3R2 gene and suggesting a possible down-regulation of PI3K/ Akt pathway. To confirm such an inhibitory effect, we investigated the Akt activation status and performed an immunoblot analysis using a specific anti phospho-Akt antibody. Expression of $A K T$ gene itself was not modulated after D6 treatment (data not shown), but its phosphorylation/activation status was decreased of about 75\% (Figure 4C). Down-modulation of $c-K I T$ gene expression was also confirmed by western blot analysis, which showed that c-kit protein level was decreased of about 65\% (Figure 4C). 


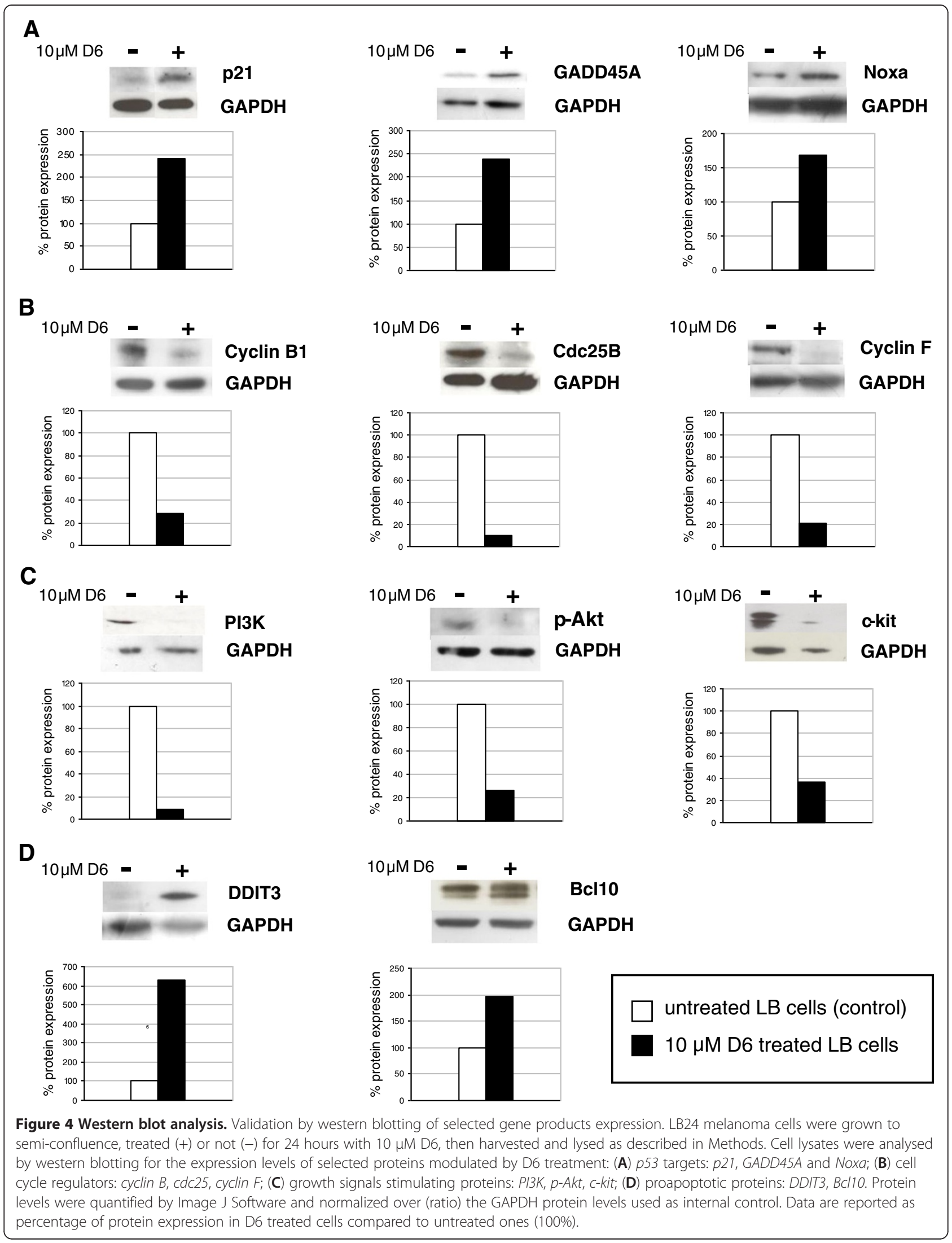


Finally, an up-modulation of the DDIT3 and Bcl10 protein expression levels upon D6 treatment was confirmed by western blot analysis (Figure 4D).

\section{Discussion}

In this paper, we demonstrate that the curcumin analogue D6 is able to enter melanoma cells reaching a peak in about two hours (see Figure 1), and give rise to a series of molecular changes that underlie the previously described anti-tumour activity of such a compound [21].

Our results indicated that D6 treatment may promote a block of cell cycle progression in G2 phase (see Figure 2) and this could represent one of the mechanisms that inhibit melanoma cells growth, as previously observed [21]. Alterations in cell cycle progression are indeed important events in cancer development and hindering such altered mechanism has been often used as a good strategy to inhibit tumour growth [27].

To investigate the possible molecular mechanisms triggered by D6 treatments, we undertook a gene expression profile analysis on melanoma cancer cells and fibroblast normal cells. Our primary objective was to identify genes that were up- or down-regulated in response to treatment, and which could be related to the phenotypic outcome. Two lists of regulated transcripts $(0.5>\mathrm{FC}>2)$, one for LB24 melanoma cells and the other for BJ fibroblasts were selected (Additional file 1-A and 2-A, respectively) and subsequently analyzed by the IPA software. Considering both the most significant functional categories and canonical pathways (see Tables 2 and 3, respectively), the activity of D6 compound in melanoma cells is certainly based on either cell stress responses either activation/repression of mechanisms regulating cell survival. Pathway analysis revealed up-regulated effectors of cell stress response and protein degradation as well as down-regulated gene products controlling cell proliferation (see Figure 3). The activation of cell defence pathways observed on melanoma cells (Table 3, pathways 1-3) indicates that D6 treatment causes important stimulation of the cellular stress response, with a strong induction of HSPs, which in turn affects cell survival and drives toward cell death [28-30]. In physiological or pathological conditions, cellular stress leads to transport and accumulation of damaged proteins in the endoplasmic reticulum where they should be repaired or committed to degradation. This stimulates the over-expression of chaperons and HSPs that perform a sort of quality control and drive seriously damaged proteins to ubiquitination and proteasome degradation. When endoplasmic reticulum functions are strongly compromised, this organelle triggers apoptotic signals in order to eliminate the irreversibly damaged cell [31]. In our model, several HSPs genes show to be up-regulated (see Table 3), and HSPA6 is the most over-expressed transcript $(\mathrm{FC}=368.61$, Table 4). It codifies for the stress inducible Hsp70B' protein, normally under-expressed or absent in most cell types, whose expression is strictly linked to that of Hsp72 (gene HSPA1A, FC $=20.35$, Table 4 ); both these proteins have a key role in mediating cell survival during endoplasmic reticulum proteotoxic stress conditions [32]. One could speculate that their huge increase of expression levels following D6 treatment could be related to the extreme endoplasmic reticulum stress response that finally directs melanoma cells to death by triggering apoptosis. In support of this hypothesis, our analysis evidenced a strong induction of the DDIT3 gene $(\mathrm{FC}=11.1$, Table 4$)$, also known as growth arrest and DNA damage-inducible gene 153 (GADD153), which is one component of the ER stress-mediated apoptosis pathway [25]. Increased expression of GADD153 by curcumin has been previously reported as one of the first steps toward apoptosis in colon cancer cells [33], thus confirming a possible contribution in this sense in D6 treated melanoma cells also.

Analogously, D6 stimulated cell stress response pathways in fibroblasts, but at a lower level compared to melanoma cells (Additional file 2-C). This is confirmed by the over-expression of single genes - like several HSPs and DDIT3 (Table 4), which is presumably milder or not sufficient to promote cell death [21].

One noteworthy feature occurring in melanoma cells upon D6 treatment - as evidenced by IPA - is an upregulation of the p53 signalling pathway (Figure 3). The p53 tumour suppressor protein is a key transcriptional regulator that responds to a variety of cellular stresses and controls key cellular processes such as DNA repair, cellcycle progression, angiogenesis, and apoptosis. The p53 protein thus acts like a "driver", which can either save injured cell by inducing damaged DNA repair and let it to re-enter cycle or sacrifice it by stimulating both cell cycle arrest and apoptosis [34,35]. In our model, up-regulation of p53 signalling pathways seems to have a key role in mediating both antiproliferative and pro-apoptotic effects of D6 on LB24 melanoma cells (see Additional file 4). Indeed, a strong up-regulation of some p53 target genes has been detected and could explain the anticancer effects of D6: $C D K N 1 A$ and $G A D D 45 A / B$ - that are strong inhibitors of cell cycle G2/M transitions [36,37], might be responsible for the block of cell cycle at G2 phase, and Noxa - a proapoptotic BH3-only protein of the Bcl-2 family, may account for the apoptotic cell death [38]. As a confirmation of this, the expression of $C D K N 1 A$ gene codifying for the CDK inhibitor p21 is about 20 times higher in treated melanoma cells $(\mathrm{FC}=19.35$, Table 4$)$. The p21 protein belongs to the Cip/Kip family of inhibitors and inactivates CDK-cyclin complexes [36,39]. In our system, it seems to regulate large part of melanoma cells response to D6 compound, being a component of most pathways identified by IPA (Table 3, pathways 4, 5, 6, 10, 11, 13, 15, 19, and 23; see also Additional files 3, 4, 5, 6, 7, 8, 10, 11, 12). 
The strong up-regulation of GADD45A and $B$ (respectively $\mathrm{FC}=7.78$ and $\mathrm{FC}=7.47$; see Table 4 ) also appears to influence several growth controlling pathways (Table 3, pathways 4, 5, 6, 10, 11, and 26; see Additional files 3, 4, 5, $6,7)$. Proteins encoded by these two stress induced genes are involved in regulation of growth and apoptosis and may cooperate in inhibiting cell growth [37,40]. Overexpression of the $\mathrm{BH} 3$-only Noxa protein codified by the PMAIP1 gene $(\mathrm{FC}=6.08$, Table 4$)$ suggests that D6 induced apoptosis could be partially p53 dependent. Noxa and Puma (p53-upregulated modulator of apoptosis) proteins are in fact direct targets in p53-mediated apoptosis at mitochondrial level $[38,41]$, functioning as "sensors" for apoptotic signals. Thus, increased Noxa levels could participate in initiating the apoptotic cascade in D6 treated melanoma cells. Supporting this hypothesis, a slight upregulation of the TP53BP2 gene has been reported in our melanoma model $(\mathrm{FC}=2.36$, Table 4$)$. This gene encodes for ASPP2, a member of the ASPP (apoptosis-stimulating protein of p53) family of p53 interacting proteins, which regulate the apoptotic function of p53 and its family members, p63 and p73. Biochemical and genetic evidences have shown that ASPP1 and ASPP2 activate the apoptotic but not the cell-cycle arrest function of p53 [42]. The increased levels of ASPP2 protein observed in D6 treated melanoma cells might thus induce p53 to trans-activate its pro-apoptotic target genes, resulting in the observed over-expression of Noxa, and subsequent activation of mitochondrial intrinsic apoptosis. Another evidence of pro-apoptotic signals in D6 treated cells expression profile is the over-expression of the BCL10 gene (FC $=3.93$, Table 4), encoding for a pro-apoptotic member of the $\mathrm{Bcl} 2$ family proteins. Bcl10 protein contains a caspase recruitment domain (CARD) motif and promotes the activation of caspase-9 [26].

The p53 signalling pathway has resulted to be significantly affected also in fibroblasts (Additional file 2-C), being $C D K N 1 A$ and $G A D D 45 A / B$ partially up-regulated. Again, this molecular response in fibroblasts is weaker than that in melanoma cells $(C D K N 1 A \mathrm{FC}=4.29$, Table 4$)$, without causing in normal cells block of proliferation or cell death.

Our analyses pointed out a down modulation of cell cycle regulators cyclin $\mathrm{B} 1, \mathrm{cdc} 25 \mathrm{~B}$, and CDK4 (Table 4), which certainly contributes to the inhibition of cell proliferation exerted by D6 on melanoma cells. Block of cell cycle in G2/M phase perfectly matches with a decrease in expression of both cyclin B (the mitotic switching cyclin) and cdc25 (the CDK1 activating phosphatase), whereas the decrease in CDK4 expression indicates that cells lack entering the cell cycle while are driven to age and die [39], as demonstrated by the G1 cell population decrease after D6 treatment (see Figure 2). Interestingly, a lower or absent down-modulation of these mitosis promoters has been evidenced in fibroblasts (Table 4), suggesting that D6 treatment specifically inhibits cell proliferation pathways in melanoma cells.

Another gene down-modulated by D6 in melanoma cells (and not in fibroblasts) is the CCNF gene ( $\mathrm{FC}=0.24$, Table 4), codifying for cyclin F, the founding member of the F-box protein family [43]. In addition to an F-box domain, cyclin F contains a cyclin-box domain, but, in contrast to typical cyclins, it does not bind or activate any cyclin-dependent kinases (CDKs). However, like other cyclins, cyclin F protein levels vary during the cell division cycle, peaking in G2. During G2, cyclin F is involved in ubiquitination and degradation of proteins [44] as well as in spindle formation and it is required for the fidelity of mitosis and genome [45]. In our system, down-modulation of such a protein is in agreement with the block of cell cycle in G2/M phase demonstrated by cytofluorimetry (Figure 2).

A further contribution to D6 anticancer activity on melanoma cells is given by the down-modulation of the $c-K I T$ proto-oncogene ( $\mathrm{FC}=0.30$, Table 4$)$. The c-kit protein belongs to class III receptor tyrosine kinases; its extracellular domain binds the SCF (stem cells factor) to stimulate several processes, including melanogenesis, gametogenesis, and haematopoiesis [46]. The $c$-KIT up-regulation is often associated with increased cell proliferation; its downregulation in D6 treated melanoma cells was confirmed by western blot analysis (Figure 4C).

One could also hypothesize that a big contribution to the anticancer activity of D6 is given by down-regulation of both phosphatidylinositol 3-kinase (PI3K) and NF-kB signalling pathways. There is growing evidence that activation of the PI3K/Akt pathway plays a significant role in melanoma (reviewed in [47]). Our results are consistent with an inhibition of PI3K/Akt pathway activation in melanoma cells following D6 treatment. As also confirmed by western blot analysis, a decreased expression of the PIK3R2 gene (FC $=0.48$, Table 4$)$, an almost complete depletion of the PI3K protein, and a $75 \%$ decrease of activated phospho-Akt have been observed in D6 treated cells (Figure 4C). In addition, a slight up-modulation of PTEN (Akt antagonist) gene expression was detected in our study $(\mathrm{FC}=1.45$, data not shown). The IкB kinase $(\mathrm{IKK}) /$ NF- $\mathrm{KB}$ signalling pathway is also often altered in tumours and NF- $\mathrm{kB}$ can affect all six hallmarks of cancer through the transcriptional activation of genes associated with cell proliferation, angiogenesis, metastasis, tumour promotion, inflammation and suppression of apoptosis (reviewed in [48]). PI3K and NF-kB signalling pathways are functionally linked, being NF-kB possibly activated by Akt kinase [49]. Our results show that, similarly to PIK3R2, NFKB1 gene expression is down-regulated by D6 in melanoma cells ( $\mathrm{FC}=0.47$ ), but it is unclear whether this could be due to the PI3K/Akt signalling repression. Deeper investigations should be made to shed light on this molecular event. 
However, it is interesting to underline that PI3K and NF$\mathrm{kB}$ pathways are both involved in curcumin anti-tumour activity [50] and inhibition of NF-kB activation may account for curcumin efficacy on cancer cells [18] and, specifically, on human melanoma cells $[19,20]$. As a consequence, it is likely that the curcumin analogue D6 shares some mechanisms of action with its natural compound, being even more effective in inhibiting tumour cells growth [21]. It is noteworthy that neither PIK3R2 nor NFKB1 genes expression was modulated in D6 treated normal fibroblasts (Table 4). Based on these considerations, we can postulate that PI3K and NF-kB signalling down-regulation is strongly related to the anticancer activity of D6 on melanoma cells.

A further consideration may be done about a possible relationship between NFKB1 under-expression and p53 signalling up-regulation. An intense crosstalk exists among these two transcription factors that activate the expression of genes with opposite functions. They are indeed competitors for the transcriptional coactivator p300/CBP [51] and, depending upon which of them (NF-kB or p53) recruits this protein, different downstream pathways will be activated, resulting in either cell proliferation or growth arrest and apoptosis [52]. To this regard, a recent report by Sen and colleagues [53] demonstrated that curcumin reverses doxorubicin resistance in breast cancer by inhibiting NF- $\kappa B$ activation and thus rescuing p300 coactivator, which in turn becomes available to the p53 transcription factor, and finally allows p53-dependent transactivation of proapoptotic proteins such as Bax, PUMA and Noxa. Based on these observations down-regulation of NF- $\mathrm{kB}$ by D6 would make the coactivator p300 available for recruitment by $\mathrm{p} 53$, thus favouring transactivation of its target genes that triggers antiproliferative and proapoptotic activity. This could be a very interesting feature of D6 because its potentiality to both inhibit NF- $\mathrm{kB}$ and, at the same time, rescue p53 signalling could be exploited either for direct therapeutic interventions against cancer, but also in combined therapies in order to sensitize resistant cancer cells to chemotherapeutic agents that can stimulate apoptosis by inducing DNA damages and triggering p53 apoptotic signals.

In summary, based on gene expression profile analysis results, we can speculate that different molecular mechanisms may contribute to the anticancer effect of D6 in melanoma cells: i) the induction of a cell stress response that triggers the ER stress-mediated apoptosis pathway; ii) the up-regulation of p53 signalling, which promotes p21and GADD45-dependent cell cycle arrest as well as mitochondrial apoptosis based on Noxa over-expression; iii) the down-modulation of several growth signals, like both PI3K and NF-kB pathways, and c-kit receptor. The diagram in Figure 5 summarizes the major gene expression changes induced by D6 in melanoma cells and hypothesizes the possible intervention of these changes in depicting cellular fate.

\section{Conclusions}

Altogether, our findings contribute to unveil the molecular mechanisms underlying the anti-tumour activity of D6 in melanoma cells. Based on such results, we can speculate that: a) p53 protein may play a key role in sustaining the anticancer effects exerted by D6 on melanoma cells; b) induction of strong cell stress responses may contribute to the reinforcement of the proapoptotic trend of p53 signalling; and c) down-modulation of several growth signals (c-kit, PI3K/Akt and NF-kB), as well as the underexpression of cell cycle regulators (cyclin B, cdc25 and CDK4) might be involved in cell growth inhibition. This last aspect seems to be peculiar of the response to D6 treatment in melanoma cells, being absent in D6-treated fibroblasts expression profile.

Although our analyses were not exhaustive, data here presented strongly indicate that a huge amount of molecular changes does participate in determining the molecular mechanism of action of D6 on melanoma cells. Gene expression profile analyses on additional melanoma cell lines are currently in progress, in order to either confirm our findings in a larger samples' collection or evaluate the effects of D6 on both primary and metastatic tumour derived cell lines.

\section{Methods}

\section{Cell cultures and D6 treatments}

Malignant melanoma LB24Dagi (LB24) cell line was obtained from the Department of Molecular and Cellular Biology at the Istituto Dermopatico dell'Immacolata (IDI) in Rome (Italy). Normal human fibroblast BJ (CRL-2522) were purchased from the American Type Culture Collection (ATCC). All cells were grown in RPMI (Invitrogen, Carlsbad, CA, USA) media, supplemented with 10\% FBS and penicillin-streptomycin (100 IU/50 $\mu \mathrm{g} / \mathrm{ml})$, as described [54]. The $\alpha \beta$-unsaturated ketone D6 [(3E,3'E)-4,4'-(5,5',6,6tetramethoxy-[1,1'-biphenyl]-3,3'-diyl)bis(but-3-en-2-one)]

(Figure 1A) has been synthesized in our lab as previously described [21]. Stock solution of D6 was prepared by dissolving D6 in DMSO to a final concentration of $100 \mathrm{mM}$ and stored at $-20^{\circ} \mathrm{C}$. Working solutions of D6 were prepared daily as previously described [21]. Cells were untreated or treated with medium containing $10 \mu \mathrm{M}$ D6 for different times depending on the experiment, then harvested with $0.25 \%$ trypsin-EDTA (Sigma-Aldrich, St. Louis, MO, USA) and processed according to the protocol of the specific analysis they have been submitted.

\section{D6 cellular uptake}

Melanoma cells were plated in T25 tissue culture flasks $\left(8 \times 10^{5}\right.$ cell/flask $)$ in complete medium; after 24 hours cells were treated or untreated with $10 \mu \mathrm{M}$ D6 for 1, 2, 4,6 or 24 hours. At each time, cells were harvested with $0.25 \%$ trypsin-EDTA solution (Sigma-Aldrich, St. Louis, 


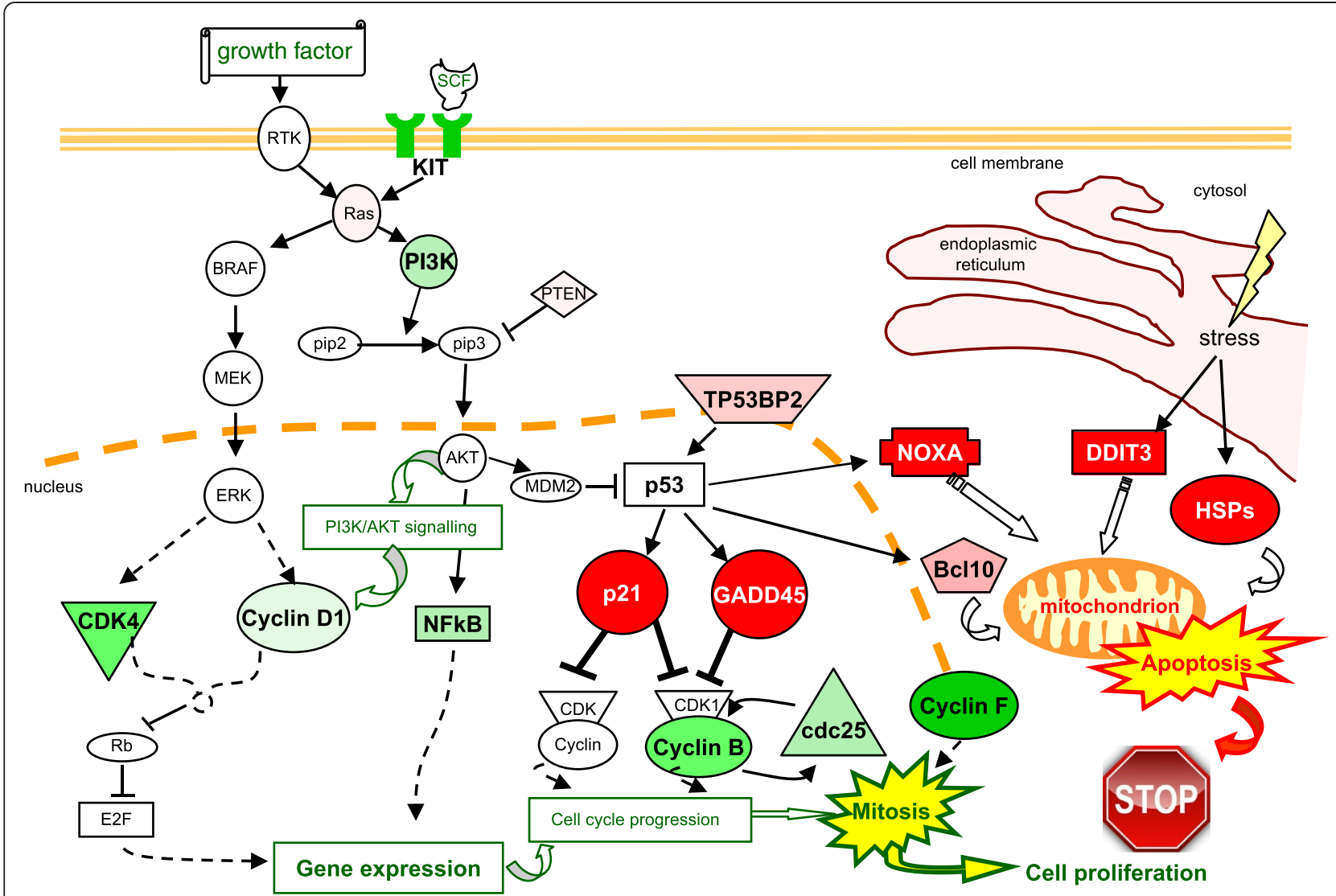

Figure 5 Summary. The diagram summarizes the major gene expression changes induced by D6 in melanoma cells, outlining their possible role in determining cell fate. Up-regulated proteins are represented in red gradations, while down-regulated ones are in green. Arrow-head lines indicate molecular activation; blunt-head lines indicate inhibition.

MO, USA), washed and resuspended in methanol $(1 \mathrm{ml})$. To achieve D6 extraction, cells in methanol were sonicated for $15 \mathrm{~min}$ and the cell lysates were centrifuged at $10,000 \mathrm{rpm}$ for $5 \mathrm{~min}$ [55]. The supernatants were transferred and stored at $-20^{\circ} \mathrm{C}$ pending analysis. Immediately prior to analysis, the samples were warmed up to room temperature. After vortexing and centrifugation, $100 \mu \mathrm{l}$ of the sample were filtered and transferred to a HPLC vial for LC/MS analysis.

\section{LC/MS analysis}

LC-grade methanol, acetonitrile, and acetic acid (AA) were purchased from Mallinckrodt J.T. Baker (Deventer, Holland). Water was purified by a Milli-Q Academic System from Millipore (Bedford, MA, USA). Syringe filters (Surfactant Free Cellulose Acetate $0.2 \mu \mathrm{m} 0.13 \mathrm{~mm}$ ) were purchased from Nalgene Company (Rochester, NY, USA).

Stock solutions of D6 were prepared by dissolving $5 \mathrm{mg}$ of D6 in $10 \mathrm{~mL}$ of DMSO (final concentration $500 \mu \mathrm{g} / \mathrm{mL}$ ). Stock solutions of D6 were stored at $-20^{\circ} \mathrm{C}$ in high-density polypropylene cryogenic-vials. Working solution of D6 was prepared daily at the concentration of $100 \mathrm{nM}$ by diluting an aliquot of the stock solutions with the solvent system (Eluent A) and was used to spike samples. Standard curves solutions of D6 at six different concentrations $(6.25,12.50$, 25,50 or $500 \mathrm{nM}$.) were obtained by adding appropriate concentrations of working solution in samples and solvent system. A 1100 series LC/MSD system (Agilent Technologies, Palo Alto, CA, USA) equipped with a diode-array detector and an autosampler (G1313A) was used for LC separation. Chromatographic separation was achieved using a Polar Plus column $(150 \mathrm{~mm} \times 2.1 \mathrm{~mm}, 3 \mathrm{~m})$ (Phenomenex, Torrance, CA, USA) fitted with a $3 \mu$ Polar Plus security guard cartridge $(4 \mathrm{~mm} \times 2.1 \mathrm{~mm})$ (Phenomenex, Torrance, CA, USA). The column temperature was maintained at $35^{\circ} \mathrm{C}$. The mobile phase consisted of Eluent A water with $0.1 \%$ HOAc and Eluent B acetonitrile. The separation was performed in a run time of $20 \mathrm{~min}$ under gradient conditions with a flow rate of $0.3 \mathrm{~mL} / \mathrm{min}$ and was followed by clean-up and equilibration stage. The gradient elution ranged from $35 \%(t=0 \mathrm{~min})$ to $65 \%$ acetonitrile $(t=20$ min). The injection volume was $10 \mu \mathrm{L}$. Mass spectrometric detection was performed using an Agilent G1946 (MSD 1100) single stage quadrupole instrument equipped 
with an electrospray atmospheric pressure ionization source. The system was calibrated with the procedures provided by Agilent; the mass spectrometer was optimized with an infusion of $0.5 \mu \mathrm{g} / \mathrm{mL}$ D6 solution at a flow rate of $100 \mu \mathrm{L} / \mathrm{min}$. The LC/MS system was programmed to divert column flow to waste for 2.5 min after injection, after which time flow was directed into the mass spectrometer that operated in positive ion mode. For quantitative measurement of analytes, selected ion monitoring (SIM) was employed. In the ESI ion source, D6 formed predominantly the ion at $m / z 411([\mathrm{M}+\mathrm{H}]+)$. The following ESI conditions were applied: drying gas (nitrogen) heated at $350^{\circ} \mathrm{C}$ at a flow rate of $9.5 \mathrm{~L} / \mathrm{min}$; nebulizer gas (nitrogen) at a pressure of $42 \mathrm{psi}$; capillary voltage in positive mode at $3500 \mathrm{~V}$; fragmentor voltage at $70 \mathrm{~V}$.

\section{Cell cycle progression analysis}

LB24 cells were plated in 6 -well plates $\left(8 \times 10^{5}\right.$ cells/well), let grown overnight and then treated with either $5 \mu \mathrm{M}$ or $10 \mu \mathrm{M}$ D6 for 24 hours. After treatments the cells were harvested with trypsin /EDTA and washed with PBS. Pellets were resuspended in 70\% cold ethanol and stored at $-20^{\circ} \mathrm{C}$ until analysis. On the day of analysis, ethanol was removed by centrifugation; pellets were washed with PBS and resuspended in $1 \mathrm{ml}$ of PBS containing $50 \mu \mathrm{g} / \mathrm{mL}$ Propidium Iodide, $100 \mu \mathrm{g} / \mathrm{mL}$ ribonuclease and $100 \mu \mathrm{g} / \mathrm{mL}$ sodium citrate (all from Sigma-Aldrich, St. Louis, MO, USA). Samples were then incubated for $30 \mathrm{~min}$ at $4^{\circ} \mathrm{C}$ in the dark and analyzed by flow cytometry using FACS Canto II (BD Biosciences, San Jose, CA, USA). Data analysis was performed using the ModFit LT 3.0 software (Verity Software House).

\section{Gene expression profile analysis}

Total RNA was isolated from LB and BJ cells, untreated or treated with $10 \mu \mathrm{M}$ D6 for 16 hours, using AllPrep DNA/RNA Mini kit (Qiagen, Inc., Chatsworth, CA) for a total of 12 RNA samples (4 samples in triplicate: LB-C 1-3, LB-D6 $1-3, B J-C_{1-3}, B J-$ D6 $_{1-3}$ ). The amount of the total RNA was detected using a NanoDrop 2000 (Thermo Fisher Scientific) and the quality was evaluated by agarose gel electrophoresis. The total RNA samples were normalized and, the mRNAs were amplified and labeled using Illumina ${ }^{\circledR}$ TotalPrep ${ }^{\mathrm{TM}}$ RNA Amplification Kit $\left(\right.$ Ambion $\left.^{\oplus}\right)$. The system uses the in vitro transcription (IVT) technology, based on the RNA amplification protocol developed by James Eberwine and coworkers [56]. The first reaction of the IVT is a reverse transcription of mRNAs, performed using an oligo(dT) primer tagged with a phage T7 promoter, and convert the mRNA fraction to single-stranded cDNA. Then, a Second-Strand Synthesis reaction converts the singlestranded cDNA in double-stranded cDNA. This product becomes the template for the in vitro transcription performed using a T7 RNA Polymerase and Biotin-NTP mix. The final results of the three reactions are hundreds to thousands of biotinylated, antisense RNA copies of each mRNA per sample. According to the manufacturer's protocol, labeled cRNAs were quantified, $750 \mathrm{ng}$ of each sample were denaturated at $65^{\circ} \mathrm{C}$ for 5 min and hybridized on a HumanHT-12 v3 Expression BeadChip (Illumina ${ }^{\circledR}$ ) at $58^{\circ} \mathrm{C}$ overnight. Each well targets 48,803 human probes, representing the whole pool of human expressed genes. After stringency washing, the signal was developed with streptavidin-Cy3, the array slide was dried by centrifugation and scanned using iScan System (Illumina ${ }^{\circledR}$ ). Images were processed and signals were quantified and normalized using GenomeStudio software (Illumina ${ }^{\circledR}$ ). Probes with detection $p$-value $>0.05$ in more than 9 out of 12 samples were excluded from the statistical analysis.

\section{Statistical analysis}

Statistical analysis was carried out on probes that showed p-values $<0.05$ in 9/12 samples, by using the BRB-Array Tools from Biometric Research Branch of National Cancer Institute - NIH (USA). We identified genes that were differentially expressed as an effect of D6 administration using a random-variance $t$-test. The random-variance $t$ test is an improvement over the standard separate t-test as it permits sharing information among genes about withinclass variation without assuming that all genes have the same variance [57]. Genes were considered statistically significant if their $p$-value was less than 0.001. A stringent significance threshold was used to limit the number of false positive findings. A per gene FDR was also computed using a univariate permutation test. Briefly, class labels of the samples were randomly permuted $\mathrm{N}$ times. For each gene, the permutation $p$-value is defined as a proportion of permutations for which the $p$-values of the univariate test are smaller than the $p$-value computed for the original labeling. Data were further filtered by fold change (FC) considering as differentially expressed probes only those showing $0.5>\mathrm{FC}>2$. The results of the tests are reported in the Additional file 1-A (LB24 melanoma cells) and 2-A (BJ fibroblasts), tabulated along with relevant statistics and hyperlink to gene annotations from the NCBI Entrez gene database. Probes passing the tests were analysed by Ingenuity Pathway Analysis (IPA) software which performs a gene set enrichment analysis and groups genes by biological functional categories and canonical pathways. The $p$-value reflects the significance of the enrichment of input genes in each functional category or pathway.

\section{Western blot}

Cells were plated in T75 tissue culture flasks in complete medium and grown to semi-confluence, then were treated for 24 hours with medium containing or not $10 \mu \mathrm{M}$ D6. 
Cells were harvested using cell-scraper and cold PBS w/o $\mathrm{Ca}^{++} / \mathrm{Mg}^{++}$(Sigma-Aldrich, St. Louis, MO, USA), and then lysed with lysis buffer ( $50 \mathrm{mM}$ Tris $\mathrm{HCl} \mathrm{pH} 7.5,5$ mM EDTA, $100 \mathrm{mM} \mathrm{NaCl}, 1 \mathrm{mM} \mathrm{Na} \mathrm{P}_{2} \mathrm{O}_{7}, 1 \%$ Triton $\mathrm{X} 100)$ plus protease inhibitor cocktail (Sigma-Aldrich, St. Louis, MO, USA). Protein concentration was determined by the QuantiPro BCA Assay Kit (Sigma-Aldrich, St. Louis, MO, USA). Protein lysates ( $30 \mu \mathrm{g}$ proteins per lane) were resolved onto $10 \%$ or $12 \%$ NuPAGE ${ }^{\circledR}$ Novex $^{\circledR}$ BisTris Mini Gels and transferred by iBlot ${ }^{\mathrm{TM}}$ Dry Blotting System to iBlot ${ }^{\circledR}$ Gel Transfer Stacks Nitrocellulose, Mini (all from Invitrogen). The membranes were then incubated with primary antibodies over night at $4^{\circ} \mathrm{C}$. Primary antibodies used were: mouse monoclonal antibodies against p21, cyclin B1, cdc25, PI3-kinase p85 $\beta$, c-kit, GAPDH or rabbit polyclonal antibodies against GADD45A, Noxa, pAKT 1/2/3 (Ser 474), all from Santa Cruz Biotechnology Inc. Detection was achieved by HRP-conjugated antimouse (Chemicon, Billerica, MA, USA, 1:10,000) or HRPconjugated anti-rabbit (Santa Cruz Biotech, 1:1,000,000) antibodies. Immune complexes were visualized with the use of an enhanced chemiluminescence system (ECL Advance $^{\mathrm{TM}}$, Amersham International). Protein levels were quantified by ImageJ software [58] and normalized over (ratio) the GAPDH protein levels used as internal control.

\section{Additional files}

Additional file 1: Melanoma cells: gene expression profile results. Excel file composed of three sheet: 1-A, 1-B, 1-C. 1-A: List of 1173 probes differentially expressed in LB24Dagi melanoma cells after 16 hours of exposure to $10 \mu \mathrm{M}$ D6. The list resulted from the statistical analysis performed by using the BRB-Array Tools as described in the Methods section. Data were filtered by fold change (FC) considering as differentially expressed probes only those showing $0.5>$ FC $>2$. In column C (Gene symbol) hyperlink to gene annotations from the NCBI Entrez gene database are supplied. 1-B: List of bio-functional categories, identified by Ingenuity Pathway Analysis (IPA) software by analysing the 1173 transcripts modulated in $10 \mu \mathrm{M}$ D6 treated LB24Dagi melanoma cells (column A). Function annotations (column B), number of genes of the input list involved in each functional category (column E) and their symbol (column F) are shown in the table. Right-tailed Fisher's exact test has been performed to calculate a $p$-value (column C) determining the probability that each biological function assigned to the selected transcripts was due to chance. $p$-values were adjusted for multiple comparisons using the Benjamini-Hochberg correction (column D). 1-C: List of canonical pathways, identified by IPA software by analysing the 1173 transcripts modulated in $10 \mu \mathrm{M}$ D6 treated LB24Dagi melanoma cells (column A). p-values (calculated using Fisher's exact test) reflect the probability that the association between the genes in the dataset and the canonical pathway is explained by chance alone (column B). The ratios in column $\mathrm{C}$ represent the number of molecules in a given pathway that meet cut-off criteria, divided by total number of molecules that make up that pathway. Genes of the input list involved in each pathway are shown in column D.

Additional file 2: Fibroblasts: gene expression profile results. Excel file composed of three sheets: 2-A, 2-B, 2-C. 2-A: List of 1883 probes differentially expressed in BJ normal fibroblasts after 16 hours of exposure to $10 \mu \mathrm{M}$ D6. The list resulted from the statistical analysis performed by using the BRB-Array Tools as described in the Methods section. Data were filtered by fold change (FC) considering as differentially expressed probes only those showing $0.5>$ FC $>2$. In column C (Gene symbol) hyperlink to gene annotations from the NCBI Entrez gene database are supplied. 2-B: List of bio-functional categories, identified by Ingenuity Pathway Analysis (IPA) software by analysing the 1883 transcripts modulated in $10 \mu \mathrm{M}$ D6 treated BJ normal fibroblasts (column A). Function annotations (column B), number of genes of the input list involved in each functional category (column E) and their symbol (column F) are shown in the table. Right-tailed Fisher's exact test has been performed to calculate a $p$-value (column C) determining the probability that each biological function assigned the selected transcripts was due to chance. $p$-values were adjusted for multiple comparisons using the Benjamini-Hochberg correction (column D). 2-C: List of canonical pathways, identified by IPA software by analysing the 1883 transcripts modulated in $10 \mu \mathrm{M}$ D6 treated BJ normal fibroblasts (column A). $p$-values (calculated using Fisher's exact test) reflect the probability that the association between the genes in the dataset and the canonical pathway is explained by chance alone (column B). The ratios in column C represent the number of molecules in a given pathway that meet cut-off criteria, divided by total number of molecules that make up that pathway. Genes of the input list involved in each pathway are shown in column D.

Additional file 3: Cell cycle: G2/M DNA checkpoint regulation. pdf file elaborated by Ingenuity Pathway Analysis (IPA) software. The diagram schematizes the "Cell cycle: G2/M DNA checkpoint regulation" pathway (n. 4 in Table 3) found to be significantly down-regulated in D6 treated melanoma cells. Up-regulated genes are represented in red gradations, down-regulated genes in green gradations. Colour intensity for each gene is proportional to its FC value.

Additional file 4: p53 signalling pathway. pdf file, elaborated by Ingenuity Pathway Analysis (IPA) software. The diagram schematizes the "p53 signalling" pathway ( $\mathrm{n}$. 5 in Table 3 ) found to be significantly induced in D6 treated melanoma cells. Up-regulated genes are represented in red gradations, down-regulated genes in green gradations. Colour intensity for each gene is proportional to its FC value.

Additional file 5: Hereditary breast cancer signalling. pdf file elaborated by Ingenuity Pathway Analysis (IPA) software. The diagram schematizes the "Hereditary breast cancer signalling" pathway (n. 10 in Table 3) found to be significantly down-regulated in D6 treated melanoma cells. Up-regulated genes are represented in red gradations, down-regulated genes in green gradations. Colour intensity for each gene is proportional to its FC value.

Additional file 6: ATM signalling. pdf file elaborated by Ingenuity Pathway Analysis (IPA) software. The diagram schematizes the "ATM signalling" pathway (n. 11 in Table 3 ) found to be significantly induced in D6 treated melanoma cells. Up-regulated genes are represented in red gradations, down-regulated genes in green gradations. Colour intensity for each gene is proportional to its FC value.

Additional file 7: Role of BRCA1 in DNA damage response. pdf file elaborated by Ingenuity Pathway Analysis (IPA) software. The diagram schematizes the "Role of BRCA1 in DNA damage response" pathway (n. 26 in Table 3) found to be significantly induced in D6 treated melanoma cells. Up-regulated genes are represented in red gradations, downregulated genes in green gradations. Colour intensity for each gene is proportional to its FC value.

Additional file 8: Role of CHK proteins in cell cycle checkpoint control. pdf file elaborated by Ingenuity Pathway Analysis (IPA) software. The diagram schematizes the "Role of CHK proteins in cell cycle checkpoint control" pathway (n. 27 in Table 3) found to be significantly down-regulated in D6 treated melanoma cells. Up-regulated genes are represented in red gradations, down-regulated genes in green gradations. Colour intensity for each gene is proportional to its FC value.

Additional file 9: Mitotic roles of Polo-like kinase. pdf file elaborated by Ingenuity Pathway Analysis (IPA) software. The diagram schematizes the "Mitotic roles of Polo-like kinase" pathway (n. 8 in Table 3 ) found to be significantly down-regulated in D6 treated melanoma cells. Up-regulated genes are represented in red gradations, down-regulated genes in green gradations. Colour intensity for each gene is proportional to its $F C$ value.

Additional file 10: Cyclins and cell cycle regulation. pdf file elaborated by Ingenuity Pathway Analysis (IPA) software. The 
diagram schematizes the "Cyclins and cell cycle regulation" pathway (n. 13 in Table 3) found to be significantly down-regulated in D6 treated melanoma cells.

Up-regulated genes are represented in red gradations, down-regulated genes in green gradations. Colour intensity for each gene is proportional to its $F C$ value.

Additional file 11: Molecular mechanisms of cancer. pdf file elaborated by Ingenuity Pathway Analysis (IPA) software. The diagram schematizes the "Molecular mechanisms of cancer" pathway (n. 23 in Table 3) found to be significant in D6 treated melanoma cells. Up-regulated genes are represented in red gradations, down-regulated genes in green gradations. Colour intensity for each gene is proportional to its FC value.

Additional file 12: Cell cycle: G1/S Checkpoint regulation. pdf file elaborated by Ingenuity Pathway Analysis (IPA) software. The diagram schematizes the "Cell cycle: G1/S Checkpoint regulation" pathway (n. 25 in Table 3) found to be significantly down-regulated in D6 treated melanoma cells. Up-regulated genes are represented in red gradations, down-regulated genes in green gradations. Colour intensity for each gene is proportional to its FC value.

\section{Competing interests}

The authors declare that they have not competing interests.

\section{Authors' contributions}

CR conceived and designed the study, coordinated it, participated to cell cultures, RNA extractions, western blot analysis, and drafted the manuscript. MF and CF together carried out statistical analysis of gene expression profile analysis data and contributed to final drafting of manuscript. AC carried out cell cultures, RNA extraction, gene expression profile analysis and contributed to statistical analysis. TC carried out gene expression profile analysis. IS and SC performed cell cultures, D6 cellular uptake assays and western blot analysis. VN participated to cell cultures and cell cycle progression analysis. GG carried out cytofluorimetric assays. AE carried out LC/MS analysis. MAD and DF performed the chemical synthesis of the curcumin-related biphenyl compound D6. GP contributed to the final drafting and critical revision of the manuscript. MP carried out cell cultures, western blot analysis and participated in study design, coordination and final drafting of the manuscript. All authors read and approved the final manuscript.

\section{Acknowledgements}

IS and SC were fellows of Sardinia Regional Government (Regione Autonoma della Sardegna). This work has been partially financed by Sardinia Autonomous Region - L.R. 7 August 2007, n.7. We thank Dr. Ana Helena Dias Francesconi for editing advices.

\section{Author details}

'Biomolecular Chemistry Institute, National Research Council of Italy. Traversa La Crucca, 3. 07100, Sassari, ITALY. ${ }^{2}$ Porto Conte Ricerche srl. Località Tramariglio, Alghero, (SS), ITALY.

\section{Received: 30 November 2012 Accepted: 26 April 2013}

Published: 4 May 2013

\section{References}

1. Berwick M, Erdei E, Hay J: Melanoma epidemiology and public health. Dermatol Clin 2009, 27:205-214.

2. Jemal A, Siegel R, Xu J, Ward E: Cancer statistics 2010. CA Cancer J Clin 2010, 60:277-300.

3. Bhatia S, Tykodi SS, Thompson JA: Treatment of metastatic melanoma: an overview. Oncology 2009, 23:488-496

4. Chapman PB, Hauschild A, Robert C, Haanen JB, Ascierto P, Larkin J, Dummer R, Garbe C, Testori A, Maio M, Hogg D, Lorigan P, Lebbe C, Jouary T, Schadendorf D, Ribas A, O'Day SJ, Sosman JA, Kirkwood JM, Eggermont AMM, Dreno B, Nolop K, Li J, Nelson B, Hou J, Lee RJ, Flaherty KT, McArthur GA, for the BRIM-3 Study Group: Improved survival with vemurafenib in melanoma with BRAF V600E mutation. N Engl J Med 2011, 364:2507-2516.
5. Ribas A, Flaherty KT: BRAF targeted therapy changes the treatment paradigm in melanoma. Nat Rev Clin Oncol 2011, 8:426-433.

6. Hodi FS, O'Day SJ, McDermott DF, Weber RW, Sosman JA, Haanen JB, Gonzalez R, Robert C, Schadendorf D, Hassel JC, Akerley W, van den Eertwegh AJM, Lutzky J, Lorigan P, Vaubel JM, Linette GP, Hogg D, Ottensmeier CH, Lebbé C, Peschel C, Quirt I, Clark Jl, Wolchok JD, Weber JS, Tian J, Yellin MJ, Nichol GM, Hoos A, Urba WJ: Improved survival with ipilimumab in patients with metastatic melanoma. N Engl J Med 2010, 363:711-723.

7. Ascierto PA, Grimaldi AM, Curti B, Faries MB, Ferrone S, Flaherty K, Fox BA, Gajewski TF, Gershenwald JE, Gogas H, Grossmann K, Hauschild A, Hodi FS, Kefford R, Kirkwood JM, Leachmann S, Maio M, Marais R, Palmieri G, Morton DL, Ribas A, Stroncek DF, Stewart R, Wang E, Mozzillo N, Marincola FM: Future perspectives in melanoma research. Meeting report from the "Melanoma Research: a bridge from Naples to the World. Napoli, December 5th-6th 2011". J. Transl Med 2012, 10:83.

8. Chin L, Garraway LA, Fisher DE: Malignant melanoma: genetics and therapeutics in the genomic era. Genes Dev 2006, 20:2149-2182.

9. Palmieri G, Capone M, Ascierto ML, Gentilcore G, Stroncek DF, Casula M, Sini MC, Palla M, Mozzillo N, Ascierto PA: Main roads to melanoma. J Trans Med 2009, 7:86:1-86:17

10. Shanmugam MK, Kannaiyan R, Sethi G: Targeting cell signaling and apoptotic pathways by dietary agents: role in the prevention and treatment of cancer. Nutr Cancer 2011, 63:161-173.

11. Jensen JD, Wing GJ, Dellavalle RP: Nutrition and melanoma prevention. Clin Dermatol 2010, 28:644-649.

12. Anand P, Sundaram C, Jhurani S, Kunnumakkara AB, Aggarwal BB: Curcumin and cancer: an "old-age" disease with an "age-old" solution. Cancer Lett 2008, 267:133-164.

13. Kunwar A, Barik A, Mishra B, Rathinasamy K, Pandey R, Priyadarsini KI: Quantitative cellular uptake, localization and cytotoxicity of curcumin in normal and tumor cells. Biochim Biophys Acta 2008, 1780:673-679.

14. Gupta SC, Prasad S, Kim JH, Patchva S, Webb LJ, Priyadarsini IK, Aggarwal BB: Multitargeting by curcumin as revealed by molecular interaction studies. Nat Prod Rep 2011, 28:1937-1955.

15. Das T, Sa G, Saha B, Das K: Multifocal signal modulation therapy of cancer: ancient weapon, modern targets. Mol Cell Biochem 2010, 336:85-95.

16. Kunnumakkara AB, Anand P, Aggarwal BB: Curcumin inhibits proliferation, invasion, angiogenesis and metastasis of different cancers through interaction with multiple cell signaling proteins. Cancer Lett 2008, 269:199225.

17. Bill MA, Bakan C, Benson DM Jr, Fuchs J, Young G, Lesinski GB: Curcumin induces proapoptotic effects against human melanoma cells and modulates the cellular response to immunotherapeutic cytokines. Mol Cancer Ther 2009, 8:2726-2735.

18. Lin $C L$, Lin JK: Curcumin: a potential cancer chemopreventive agent trough suppressing NF-kB signalling. J Cancer Mol 2008, 4:11-16.

19. Zheng M, Ekmekcioglu S, Walch ET, Tang CH, Grimm EA: Inhibition of nuclear factor-kappaB and nitric oxide by curcumin induces $\mathrm{G} 2 / \mathrm{M}$ cell cycle arrest and apoptosis in human melanoma cells. Melanoma Res 2004, 14:165-171.

20. Siwak DR, Shishodia S, Aggarwal BB, Kurzrock R: Curcumin-induced antiproliferative and proapoptotic effects in melanoma cells are associated with suppression of IkappaB kinase and nuclear factor kappaB activity and are independent of the B-Raf/mitogen-activated/extracellular signal-regulated protein kinase pathway and the Akt pathway. Cancer 2005, 104:879-890.

21. Pisano M, Pagnan G, Dettori MA, Cossu S, Caffa I, Sassu I, Emionite L, Fabbri D, Cilli M, Pastorino F, Palmieri G, Delogu G, Ponzoni M, Rozzo C: Enhanced anti-tumor activity of a new curcumin-related compound against melanoma and neuroblastoma cells. Mol Cancer 2010, 9:137:1-137:12.

22. Carr KM, Bittner M, Trent JM: Gene-expression profiling in human cutaneous melanoma. Oncogene 2003, 22:3076-3080.

23. Hoek KS: DNA microarray analyses of melanoma gene expression: a decade in the mines. Pigment Cell Res 2007, 20:466-484.

24. Curtin JA, Busam K, Pinkel D, Bastian BC: Somatic activation of KIT in distinct subtypes of melanoma. J Clin Oncol 2006, 24:4340-4346.

25. Oyadomari S, Mori M: Roles of CHOP/GADD153 in endoplasmic reticulum stress. Cell Death Differ 2004, 11:381-389.

26. Yan M, Lee J, Schilbach S, Goddard A, Dixit V: mE10, a novel caspase recruitment domain-containing proapoptotic molecule. J Biol Chem 1999, 274:10287-10292. 
27. McDonald ER 3rd, El-Deiry WS: Cell cycle control as a basis for cancer drug development. Int J Oncol 2000, 16:871-886.

28. Nollen EA, Morimoto RI: Chaperoning signaling pathways: molecular chaperones as stress-sensing 'heat shock' proteins. J Cell Sci 2002, 115:2809-2816.

29. Massé D, Ebstein F, Bougras G, Harb J, Meflah K, Grégoire M: Increased expression of inducible HSP70 in apoptotic cells is correlated with their efficacy for antitumor vaccine therapy. Int J Cancer 2004, 111:75-83.

30. Carta F, Demuro PP, Zanini C, Santona A, Castiglia D, D'Atri S, Ascierto PA, Napolitano M, Cossu A, Tadolini B, Turrini F, Manca A, Sini MC, Palmieri G, Rozzo C: Analysis of candidate genes through a proteomics-based approach in primary cell lines from malignant melanomas and their metastases. Melanoma Res 2005, 15:235-244.

31. Oyadomari S, Araki E, Mori M: Endoplasmic reticulum stress mediated apoptosis in pancreatic beta-cells. Apoptosis 2002, 7:335-345.

32. Noonan EJ, Place RF, Giardina C, Hightower LE: Hsp70B' regulation and function. Cell Stress Chaperones 2007, 12:219-229.

33. Scott DW, Loo G: Curcumin-induced GADD153 gene up-regulation in human colon cancer cells. Carcinogenesis 2004, 25:2155-2164.

34. Erol A: Deciphering the intricate regulatory mechanisms for the cellular choice between cell repair, apoptosis or senescence in response to damaging signals. Cell Signal 2011, 23:1076-1081.

35. Aylon Y, Oren M: Living with p53, dying of p53. Cell 2007, 130:597-600.

36. Abbas T, Dutta A: p21 in cancer: intricate networks and multiple activities. Nat Rev Cancer 2009, 9:400-414.

37. Cretu A, Sha X, Tront J, Hoffman B, Liebermann DA: Stress sensor Gadd45 genes as therapeutic targets in cancer. Cancer Ther 2009, 7:268-276.

38. Oda E, Ohki R, Murasawa H, Nemoto J, Shibue T, Yamashita T, Tokino T, Taniguchi T, Tanaka N: Noxa, a BH3-only member of the Bcl-2 family and candidate mediator of p53-induced apoptosis. Science 2000, 288:1053-1058.

39. Vermeulen $K$, Van Bockstaele DR, Berneman ZN: The cell cycle: a review of regulation, deregulation and therapeutic targets in cancer. Cell Prolif 2003, 36:131-149.

40. Tamura RE, de Vasconcellos JF, Sarkar D, Liebermann TA, Fisher PB, Zerbini LF: GADD45 proteins: central players in tumorigenesis. Curr. Mol. Med 2012, 12:634-651.

41. Huang DCS, Strasser A: BH3-Only Proteins - Essential Initiators of Apoptotic Cell Death. Cell 2000, 103:839-842.

42. Sullivan A, Lu X: ASPP: a new family of oncogenes and tumour suppressor genes. Br J Cancer 2007, 96:196-200.

43. Bai C, Sen P, Hofmann K, Ma L, Goebl M, Harper JW, Elledge SJ: SKP1 connects cell cycle regulators to the ubiquitin proteolysis machinery through a novel motif, the F-box. Cell 1996, 86:263-274.

44. Cardozo T, Pagano M: The SCF ubiquitin ligase: insights into a molecular machine. Nature Rev Mol Cell Biol 2004, 5:739-751.

45. D'Angiolella V, Donato V, Vijayakumar S, Saraf A, Florens L, Washburn MP, Dynlacht B, Pagano M: SCF Cyclin F controls centrosome homeostasis and mitotic fidelity through CP110 degradation. Nature 2010, 466:138-142.

46. Ashman LK: The biology of stem cell factor and its receptor C-kit. Int Biochem Cell Biol 1999, 31:1037-1051.

47. Davies MA: The role of the PI3K-AKT pathway in melanoma. Cancer J 2012, 18:142-147.

48. Baud V, Karin M: Is NF-kappaB a good target for cancer therapy? Hopes and pitfalls. Nat Rev Drug Discov 2009, 8:33-40.

49. Ozes ON, Mayo LD, Gustin JA, Pfeffer SR, Pfeffer LM, Donner DB: NF-kappaB activation by tumour necrosis factor requires the Akt serine-threonine kinase. Nature 1999, 401:82-85.

50. Kuttan G, Kumar KB, Guruvayoorappan C, Kuttan R: Antitumor, antiinvasion, and antimetastatic effects of curcumin. Adv Exp Med Biol 2007, 595:173-184.

51. Webster GA, Perkins ND: Transcriptional cross talk between NF-kappaB and p53. Mol Cell Biol 1999, 19:485-3495.

52. Iyer NG, Chin SF, Ozdag H, Daigo Y, Hu DE, Cariati M, Brindle K, Aparicio S, Caldas C: p300 regulates p53-dependent apoptosis after DNA damage in colorectal cancer cells by modulation of PUMA/p21 levels. Proc Natl Acad Sci U S A 2004, 101:7386-7391.

53. Sen GS, Mohanty S, Hossain DM, Bhattacharyya S, Banerjee S, Chakraborty J, Saha S, Ray P, Bhattacharjee P, Mandal D, Bhattacharya A, Chattopadhyay S, Das T, Sa G: Curcumin enhances the efficacy of chemotherapy by tailoring p65NFkappaB-p300 cross-talk in favor of p53-p300 in breast cancer. J Biol Chem 2011, 286:42232-42247.
54. Pisano M, Pagnan G, Loi M, Mura ME, Tilocca MG, Palmieri G, Fabbri D, Dettori MA, Delogu G, Ponzoni M, Rozzo C: Antiproliferative and pro-apoptotic activity of eugenol-related biphenyls on malignant melanoma cells. Mol Cancer 2007, 6:8:1-8:1.

55. Kunwar A, Barik A, Pandey R, Priyadarsini Kl: Transport of liposomal and albumin loaded curcumin to living cells: an absorption and fluorescence spectroscopic study. Biochim Biophys Acta 2006, 1760:1513-1520.

56. Van Gelder RN, von Zastrow ME, Yool A, Dement WC, Barchas JD, Eberwine $\mathrm{JH}$ : Amplified RNA synthesized from limited quantities of heterogeneous cDNA. Proc Natl Acad Sci U S A 1990, 87:1663-1667.

57. Wright GW, Simon RM: A random variance model for detection of differential gene expression in small microarray experiments. Bioinformatics 2003, 19:2448-2455.

58. Schneider CA, Rasband WS, Eliceiri KW: NIH Image to ImageJ: 25 years of image analysis. Nat Met 2012, 9:671-675.

doi:10.1186/1476-4598-12-37

Cite this article as: Rozzo et al:: Molecular changes induced by the curcumin analogue D6 in human melanoma cells. Molecular Cancer 2013 12:37.

\section{Submit your next manuscript to BioMed Central and take full advantage of:}

- Convenient online submission

- Thorough peer review

- No space constraints or color figure charges

- Immediate publication on acceptance

- Inclusion in PubMed, CAS, Scopus and Google Scholar

- Research which is freely available for redistribution 